\title{
Comparing Strategies for Lipid Lowering in Argentina: An Analysis from the CVD Policy Model-Argentina
}

\author{
Jonatan Konfino, MSC ${ }^{7}$, Alicia Fernandez, $\mathrm{MD}^{1,2}$, Joanne Penko, MPH², Antoinette Mason, $\mathrm{MS}^{3}$, \\ Eugenio Martinez, MS', Pamela Coxson, $P h D^{2}$, David Heller, MD ${ }^{5}$, Andrew Moran, MPH $H^{6,7}$, \\ Kirsten Bibbins-Domingo, $P h D^{2}$, Eliseo J. Pérez-Stable, MD ${ }^{8,9}$, and Raul Mejía, PhD $1,2,3,4,5,6,7,7,9,9,10$
}

\footnotetext{
'Centro de Estudios de Estado y Sociedad (CEDES), Buenos Aires, Argentina; ${ }^{2}$ Division of General Internal Medicine, Department of Medicine, University of California San Francisco, San Francisco, CA, USA; ${ }^{3}$ University of California San Diego School of Medicine, La Jolla, CA, USA; ${ }^{4}$ Instituto de Investigaciones Económicas, Facultad de Cs. Económicas, Universidad Nacional de Salta, Salta, Argentina; ${ }^{5}$ Arnhold Institute for Global Health, Icahn School of Medicine at Mount Sinai, New York, NY, USA; ${ }^{6}$ Division of General Internal Medicine, Columbia University Medical Center, New York, NY, USA; ${ }^{7}$ New York College of Physicians and Surgeons, Columbia University, New York, NY, USA; ${ }^{8}$ Division of General Internal Medicine,

Department of Medicine, Medical Effectiveness Research Center for Diverse Populations, University of California San Francisco, San Francisco, CA, USA; ${ }^{9}$ Office of the Director, National Institute of Minority Health and Health Disparities, National Institutes of Health, Bethesda, MD, USA; ${ }^{10} \mathrm{Hospital}$ de Clinicas, University of Buenos Aires, Buenos Aires, Argentina.
}

INTRODUCTION: In Argentina, the national guidelines for lipid control emphasize the use of relatively inexpensive low- or moderate-potency statins by patients at high risk $(>20 \%)$ of a cardiovascular event. The objective of this study was to compare the impact and costs of the current national CVD prevention guidelines with regard to morbidity and mortality in Argentina with the impact and costs of three strategies that incorporate high-potency statins.

METHODS: We used the CVD Policy Model-Argentina to model the proposed interventions. This model is a national-scale, state-transition (Markov) computer simulation model of the CVD incidence, prevalence, mortality, and costs in adults 35-84 years of age. We modeled three scenarios: scenario 1 lowers the risk threshold for treatment to $>10 \%$ according the Framingham Risk Score (FRS); scenario 2 intensifies statin potency under current treatment thresholds; and scenario 3 combines both scenarios by lowering the treatment threshold to $\geq 10 \%$ FRS and intensifying statin potency.

RESULTS: Scenario 1 would translate into 1400 fewer MIs and 500 fewer CHD deaths every year, a $3 \%$ and $2 \%$ reduction, respectively. Scenario 2 would lead to 2000 fewer MIs and 1000 fewer CHD deaths every year. Scenario 3 would result in the greatest reduction in MIs and CHD deaths, with 3400 fewer MIs and 1400 fewer CHD deaths every year, which translates to a $7 \%$ and $6 \%$ reduction, respectively. All scenarios were cost-effective if the cost of a high-potency statin pill was under US\$0.25. CONCLUSION: Incorporating those individuals with greater than $10 \%$ cardiovascular risk and the use of high-potency statins into Argentina's national lipid guidelines could result in fewer CHD deaths and events at a reasonable cost.

Electronic supplementary material The online version of this article (doi:10.1007/s11606-016-3907-8) contains supplementary material, which is available to authorized users.

Received March 2, 2016

Revised September 15, 2016

Accepted October 14, 2016

Published online November 16, 2016
KEY WORDS: cardiovascular disease; Argentina; statin; coronary heart disease; hydroxy-3-methylglutaryl-coenzyme A reductase inhibitor; prevention.

J Gen Intern Med 32(5):524-33

DOI: $10.1007 / \mathrm{s} 11606-016-3907-8$

(c) Society of General Internal Medicine 2016

\section{INTRODUCTION}

Cardiovascular disease (CVD) is the leading cause of death in Argentina, and is responsible for $34 \%$ of total deaths. ${ }^{1}$ Recent data indicate that the prevalence of hyperlipidemia, hypertension, and diabetes, already among the highest in Latin America, is increasing. ${ }^{2}$ The search for efficient and costeffective strategies to improve primary and secondary prevention of cardiovascular disease is a national priority. Although lipid control represents one of the most effective strategies for reducing CVD risk, in Argentina (as in much of the rest of the world), cholesterol medications are underused, and only about $34 \%$ of those with a diagnosis of hypercholesterolemia ${ }^{2}$ and $15 \%$ of individuals requiring secondary prevention ${ }^{3}$ report using a medication to reduce low-density lipoprotein cholesterol (LDL-C). By contrast, although in the United States only $19 \%$ of the population aged 30-79 are on statins, this percentage increases to $58 \%$ among people with coronary artery disease. $^{4}$

Statins are efficacious for primary and secondary prevention, and their use is a key recommendation of international CVD prevention guidelines. ${ }^{5,}{ }^{6}$ More recent international guidelines emphasize the use of high-potency statins ${ }^{7,8}$ and suggest lowering treatment thresholds for primary prevention for patients whose overall risk profile conveys moderate cardiac risk. The 2013 American College of Cardiology/ American Heart Association (ACC/AHA) guideline on the treatment of blood cholesterol recommends high-potency statins for individuals with a clinical history of CVD or with LDL-C $\geq 190 \mathrm{mg} / \mathrm{dL}$; moderate-potency statins for diabetics 
aged 40-75; and moderate- to high-potency statin therapy for primary prevention in those aged 40-75 with CVD risk of $7.5 \%$ or higher. $^{9}$

In Argentina, the guidelines released by the Ministry of Health in 2009 recommend simvastatin for primary prevention in patients with diabetes or with $20 \%$ or greater chance of having a myocardial infarction in the next 10 years, according to the Pan-American Heart Organization Cardiovascular Risk Calculator for Latin America, region B. ${ }^{10}$ In Argentina, however, the cost-effectiveness of using high- versus moderatepotency statins for secondary prevention and for high-risk primary prevention is unknown. As many Argentines fall into a moderate-risk category, with a 10-19\% chance of developing a cardiac event over 10 years, the cost-effectiveness of a broadened approach to primary prevention would also need to be established. This lack of data can impede decision-making, particularly among policymakers responsible for government health and medication programs, who must consider whether limited resources should be directed toward higher-cost medications versus other priorities such as expanding the reach of current guidelines.

In order to help address these urgent policy questions, we used a well-established computer simulation model to determine the impact on morbidity and mortality in Argentina of a) using high-potency statins to treat individuals with diabetes or $20 \%$ or greater chance of experiencing a CVD event over the next 10 years; b) using simvastatin or other moderate-potency statins to treat people with $10 \%$ or greater chance of a CVD event over the next 10 years; and to determine c) the costeffectiveness of each approach from the perspective of the national government, which both administers a large national medication program for low-income people and bears the cost of hospitalization for their CVD events.

\section{METHODS}

\section{Cardiovascular Disease Policy Model- Argentina}

The CVD Policy Model is a national-scale, state-transition (Markov) computer simulation model of the coronary heart disease and stroke incidence, prevalence, mortality, and costs in adults 35-84 years of age, originally developed for the United States and used for over 25 years to forecast CVD trends and simulate the impact of CVD interventions in the US. ${ }^{11,12}$ The model was adapted for the population of Argentina using Argentina-specific demographic and epidemiologic inputs wherever possible, and calibrating to reproduce CVD events and deaths observed in the Argentine population. The CVD Policy Model-Argentina has been used previously to evaluate population-wide policies aimed at tobacco control ${ }^{13}$ and dietary salt restriction ${ }^{14,15}$ (see Supplementary Online Appendix 1 for details).

The model is composed of three sub-models: the demographic-epidemiological sub-model, the bridge sub-model, and the disease history sub-model. The demographic-epidemiological sub-model predicts coronary heart disease (CHD) and stroke incidence and non-CVD mortality in the population without CVD stratified by age, sex, and six modifiable risk factors: smoking status (active smoker or secondhand smokeexposed or no exposure), systolic blood pressure (SBP), highdensity lipoprotein cholesterol (HDL-C), LDL-C, use of medication to lower cholesterol (statins, other drugs, or no use), and presence or absence of diabetes mellitus. The incidence of CHD, stroke, and non-CVD death is determined by beta coefficients estimated from Framingham Heart Study Original Cohort (exams 13-28) and Offspring Cohort (exams 1-7) data using the counting process extension of the Cox proportional hazards model, which allows for time-dependent covariates. ${ }^{16-20}$ For the fraction of the population developing CVD, the bridge sub-model characterizes the initial CVD event and related events over the next 30 days. The disease history sub-model then predicts the rate of subsequent CVD events and deaths, stratified by age, sex, and CVD event history (Fig. 1). The model is written in Fortran 95 and compiled using the Lahey Fortran 95 compiler v7.2 (Lahey Computer Systems, Incline Village, NV). Table 1 summarizes the data sources for the CVD Policy Model-Argentina.

A more detailed explanation of the CVD Policy Model and its translation to the Argentine population can be found in supplementary Online Appendix 1.

\section{Modeling Assumptions and Simulated Interventions}

We modeled four statin interventions, including one simulation representing wider implementation of current Argentine statin use guidelines and three scenarios reflecting variations to national guidelines, with input assumptions as detailed in Table 2. For our main simulations, we assumed $50 \%$ compliance among those who qualify for a statin under the given scenario but are not currently taking a statin. The four simulated interventions were as follows:

(1) Current guidelines. For those without a history of cardiovascular disease, we treated $50 \%$ of those not on a statin who had either greater than $20 \%$ cardiovascular risk based on the Framingham Risk Score (FRS) or a history of diabetes. For those with a history of CVD, we assumed that $15 \%$ were already on a statin, based on responses to a national survey ${ }^{3}$, and treated $50 \%$ of the remaining CVD population. In alignment with current national guidelines, those newly treated were assumed to be on a moderate-dose statin (such as simvastatin $40 \mathrm{mg}$ ), with a corresponding decrease in mean LDL-C of $40 \% .^{29,30}$

(2) Scenario 1 - expansion of primary prevention target population. For scenario 1, we treated the population described for the current guidelines scenario and expanded the primary prevention population to include $50 \%$ of treatment-naïve individuals with an FRS score 


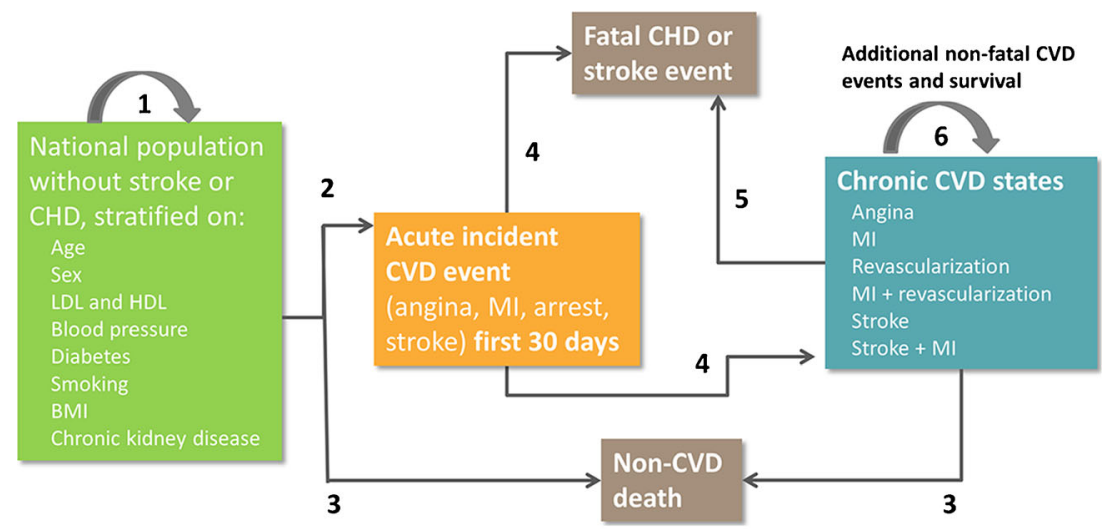

*The CVD Policy Model is a state-transition simulation model of CVD in adults. State transitions are numbered in the diagram: Transition $1=$ remain in CVD-free state; Transition $2=$ incident CVD; Transition $3=$ non-CVD death; Transition 4 and $5=$ survival or case fatality; Transition $6=$ survival with or without repeat CVD event in chronic CVD patients. $\mathrm{LDL}=$ low density lipoprotein cholesterol; $\mathrm{HDL}=$ high density lipoprotein cholesterol; $\mathrm{BMI}=$ body mass index $; \mathrm{MI}=$ myocardial infarction .

Fig. 1 Cardiovascular disease (CVD) policy model structure.

of 10-20\%, assuming treatment with a moderate-dose statin.

(3) Scenario 2 - use of high-potency statins with current guideline's target population. For scenario 2, we treated the same population as described for the current guideline scenario, but simulated the effects of a highpotency statin (such as atorvastatin $40-80 \mathrm{mg}$, or rosuvastatin $20-40 \mathrm{mg}$ ), with an assumed decrease in LDL-C of $55 \% .{ }^{29,} 30$ Those already taking a statin were assumed to experience the incremental benefit of moving from a moderate-dose to a high-potency statin.

(4) Scenario 3 - expansion of primary prevention and use of high-potency statin with high-risk population. Scenario 3 involved a combination of interventions in scenarios 1 and 2, with those qualifying under current national guidelines treated with a high-potency statin and those with no history of CVD but an FRS score of $10-20 \%$ treated with a moderate-dose statin.

We conducted 10-year simulations for the adult population of Argentina aged 35-84 years, a relevant time frame for nearterm decision-making by the Argentine government. Results from scenarios 1,2, and 3 were compared to those from the current guidelines simulation to describe the impact of alterations to national guidelines on myocardial infarctions, CHD deaths, and cost-effectiveness outcomes. All four scenarios were compared to a baseline simulation assuming current levels of statin use as observed in national surveys to determine the numbers needed to treat under each scenario to prevent one MI or CHD death over 10 years.

Table 1 Data Sources for the Cardiovascular Disease (CVD) Policy Model-Argentina

\begin{tabular}{|c|c|}
\hline$\overline{\text { Data }}$ & Source \\
\hline $\begin{array}{l}\text { Population of Argentina and incoming 35-year-old } \\
\text { persons, 2010-2050 }\end{array}$ & Argentina National Statistics and Census Institute ${ }^{21}$ \\
\hline \multicolumn{2}{|l|}{ Prevalence } \\
\hline Risk factor (means and distributions) & $\begin{array}{l}2009 \text { National Risk Factors Survey, Ministry of Health } \\
\text { Cardiovascular Risk Factor Multiple Evaluation in Latin America (CARMELA) Study }\end{array}$ \\
\hline \multicolumn{2}{|r|}{ 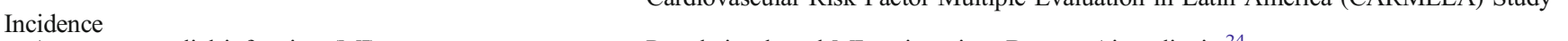 } \\
\hline Acute myocardial infarction (MI) & Population-based MI registry in a Buenos Aires district ${ }^{24}$ \\
\hline Stroke & National Hospital Discharge Registry ${ }^{25}$ \\
\hline MI and stroke prevalence 2010 & Population-based risk factor telephone survey in Buenos Aires, Ministry of Health ${ }^{10}$ \\
\hline \multicolumn{2}{|l|}{ Mortality } \\
\hline Coronary heart disease* & Statistics and Information Department, Ministry of Health ${ }^{25}$ \\
\hline Stroke $^{\ddagger}$ & Statistics and Information Department, Ministry of Health ${ }^{25}$ \\
\hline \multicolumn{2}{|l|}{ One-day and 28-day CHD case fatality } \\
\hline CHD & $\begin{array}{l}\text { Argentine national hospital survey }{ }^{26} \\
\text { Ministry of Health admissions database }{ }^{25}\end{array}$ \\
\hline Stroke & Argentine National Registry (RENACER) ${ }^{27}$ \\
\hline Stroke 28 -day case fatality & Iquique Stroke Study (PISCIS) ${ }^{28}$ \\
\hline
\end{tabular}

*International Classification of Diseases, 10th revision (ICD-10) codes I21, I22 for myocardial infarction; ICD-10 codes I20, I23-I25 for angina and other CHD; ICD-10 codes I461, I469, I472, I490, I460, I500, I501, I509, I514, I515, I516, I519, I709 for poorly defined cardiovascular disease events and death

${ }^{7}$ ICD-10 codes I60-I69 for stroke deaths 
Table 2 Input Parameters and Assumptions for CVD Policy Model Simulations

\begin{tabular}{|c|c|c|c|}
\hline Parameter & Base case value & $\begin{array}{l}\text { Range for sensitivity } \\
\text { analyses }\end{array}$ & Reference \\
\hline \multicolumn{3}{|l|}{ Treatment-associated reduction in LDL-C, \% } & \multirow[t]{3}{*}{29,30} \\
\hline Moderate-potency & 40 & $36-44$ & \\
\hline High-potency & 54.77 & $50.77-58.77$ & \\
\hline \multicolumn{3}{|l|}{ Annual cost of statin treatment (US $\$ /$ person treated) } & \multirow[t]{3}{*}{31} \\
\hline Moderate-potency & 43.80 & $21.90-65.70$ & \\
\hline High-potency & 91.25 & $45.63-136.88^{*}$ & \\
\hline Treatment compliance/adherence & $50 \%$ & $25 \%-75 \%{ }^{\dagger}$ & \multirow{5}{*}{$\underset{32,33}{\text { Assumed }}$} \\
\hline \multicolumn{3}{|l|}{ Costs associated with medication management } & \\
\hline Physician visit at treatment initiation & 12.90 & $6.45-19.35$ & \\
\hline Liver panel at treatment initiation & 9.16 & $4.58-13.74$ & \\
\hline Annual lipid panel during treatment & 12.60 & $6.30-18.90$ & \\
\hline \multicolumn{4}{|l|}{ Costs and QALY decrements from adverse events } \\
\hline \multicolumn{4}{|l|}{ Myopathy } \\
\hline Annual risk of episode & 0.0001 & & 29 \\
\hline Annual QALY penalty per episode & 0.00996 & $0.00498-0.0149$ & 34 \\
\hline Annual cost, \&/episode & 33.51 & $\begin{array}{l}0.00490-0.0149 \\
16.76-50.27\end{array}$ & 32,33 \\
\hline \multicolumn{4}{|l|}{ Stroke } \\
\hline Annual risk of episode & 0.0001 & & 29 \\
\hline Annual QALY penalty per episode & 0.3120 & $0.156-0.468$ & 34 \\
\hline Annual cost, \&/episode & 1083.69 & $541.85-1625.54$ & 32,33 \\
\hline \multicolumn{4}{|l|}{ Diabetes } \\
\hline Annual risk of episode & 0.00098 & $0.00029-0.001667$ & 35 \\
\hline Annual QALY penalty per episode ${ }^{\S}$ & 0.0762 & $0.0381-0.114$ & 34 \\
\hline Annual cost, \&/episode & 4451.1 & $2225.55-6676.65$ & 32,33 \\
\hline Annual discount rate & $3 \%$ & $0-5 \%{ }^{\dagger}$ & Assumed \\
\hline
\end{tabular}

\section{Cost-Effectiveness Estimates}

Health care costs were estimated from the perspective of the health care system, and treatment costs assumed the direct cost of statin pills, medication management costs including laboratory tests and physician visits, and costs associated with adverse events including myopathy, diabetes, and stroke (Table 2). Indirect costs such as work loss or family assistance were not included in the analysis. Health care costs were obtained from Ministry of Health publications ${ }^{36}$ the National Institute of Statistics and Census, ${ }^{37}$ reviews from non-governmental organizations, ${ }^{32}, 33,38,39$ and published papers in peer-reviewed journals. $^{40-42}$ The estimated cost per person per year of statin treatment was based on the direct cost of medications that the government currently pays for moderate-potency statins. Costs for moderate-potency statins were US\$0.12 per day. ${ }^{43}$ To estimate the cost of high-potency statins from the government's perspective, we applied a price ratio of high- to moderatepotency statins based on the average over-the-counter price difference between atorvastatin $40 \mathrm{mg}$ pill (high) and simvastatin $40 \mathrm{mg}$ pill (moderate), which yielded a ratio of 2.08 for high- to moderate-potency costs. ${ }^{31}$ Based on this adjustment, we estimated that a high-potency statin would cost US $\$ 0.25$ per day.

Model inputs for QALYs associated with cardiovascular disease outcomes were derived from the Global Burden of Disease study. ${ }^{34}$ In each of our statin intervention simulations, we included quality-of-life decrements associated with adverse events, but excluded QALYS for the burden of taking a pill every day (Table 2), with our base case analyses assuming the same rate of toxicity for moderateand high-potency statins. In our base case simulations, we used an annual discount rate of $3 \%,{ }^{44}$ with costs and QALYs discounted at the same rate. All monetary values are expressed in current US dollars at December 2013 conversion rates.

\section{Sensitivity Analyses}

We used both probabilistic and deterministic analyses to evaluate the sensitivity of our findings to our input assumptions. Monte Carlo simulations were used to generate $95 \%$ confidence interval $(95 \% \mathrm{CI})$ around our primary outcomes measures for each intervention scenario. In addition to inputs relating to statin effectiveness, costs, and QALYs described in Table 2, we also varied beta values defining the relationship between LDL-C and incident CHD. There were 1000 random draws from a standard normal distribution, scaled to the mean and confidence interval for each varied parameter. The Monte Carlo program was written in Python and results analyzed using Microsoft Excel 2010. We used deterministic approaches to evaluate the sensitivity of our results to assumptions about the degree of statin compliance (range evaluated: 25-75\%), the discount rate (range evaluated: $0-5 \%$ ), and the rate of toxicity in moderate- vs. high-potency statins (sensitivity analysis assumed twofold greater toxicity for high-potency statins). 
Table 3 Projected Average Annual Myocardial Infarctions, Coronary Heart Disease Deaths and Quality-Adjusted Life Years, and Changes in these Outcomes Relative to Expanding Statin Use Under Current Guidelines, Estimated Using the CVD Policy Model-Argentina

\begin{tabular}{|c|c|c|c|c|c|c|c|}
\hline $\begin{array}{l}\text { Simulation } \\
\text { scenario }\end{array}$ & $\begin{array}{c}\text { Average } \\
\text { annual } \\
\text { number } \\
\text { treated }^{\S}\end{array}$ & $\begin{array}{l}\text { Total MIs } \\
\quad(95 \% \text { UI })\end{array}$ & $\begin{array}{l}\% \text { Change } \\
\text { in } \mathrm{MI}^{\dagger}\end{array}$ & $\begin{array}{l}\text { Total CHD } \\
\text { deaths } \\
(95 \% \text { UI })\end{array}$ & $\begin{array}{c}\text { \% Change } \\
\text { in CHD } \\
\text { deaths }^{\dagger}\end{array}$ & Total QALYs & $\begin{array}{l}\text { Change in } \\
\text { QALYs } \\
(95 \% \text { UI })^{\dagger}\end{array}$ \\
\hline $\begin{array}{l}\text { Current guidelines } \\
\text { (comparator) }\end{array}$ & $3,700,900$ & $\begin{array}{l}47,300 \\
(46,100-48,500)\end{array}$ & & $\begin{array}{l}23,000 \\
(22,500-23,400)\end{array}$ & & $\begin{array}{l}15,633,000 \\
(15,632,000-15,634,000)\end{array}$ & \\
\hline $\begin{array}{l}\text { Scenario } 1 \text { : lower } \\
\text { primary prevention } \\
\text { treatment threshold } \\
\neq\end{array}$ & $4,900,800$ & $\begin{array}{l}45,900 \\
(44,600-47,170)\end{array}$ & $-3.03 \%$ & $\begin{array}{l}22,500 \\
(21,900-23,000)\end{array}$ & $-2.13 \%$ & $\begin{array}{l}15,635,000 \\
(15,634,000-15,637,000)\end{array}$ & $\begin{array}{l}2500 \\
(1500-3500)\end{array}$ \\
\hline $\begin{array}{l}\text { Scenario 2: use high- } \\
\text { potency statin for } \\
\text { high-risk patients }\end{array}$ & $3,700,900$ & $\begin{array}{l}45,300 \\
(43,900-46,700)\end{array}$ & $-4.24 \%$ & $\begin{array}{l}22,000 \\
(21,300-22,600)\end{array}$ & $-4.35 \%$ & $\begin{array}{l}15,636,000 \\
(15,634,000-15,638,000)\end{array}$ & $\begin{array}{l}3300 \\
(2300-4300)\end{array}$ \\
\hline $\begin{array}{l}\text { Scenario 3: use high- } \\
\text { potency statins for } \\
\text { those at risk under } \\
\text { current guidelines } \\
\ddagger ; \text { use moderate- } \\
\text { potency with those } \\
10-20 \% \text { FRS }\end{array}$ & $5,000,900$ & $\begin{array}{l}44,000 \\
(42,400-45,500)\end{array}$ & $-7.11 \%$ & $\begin{array}{l}21,500 \\
(20,800-22,200)\end{array}$ & $-6.30 \%$ & $\begin{array}{l}15,638,500 \\
(15,636,000-15,641,000)\end{array}$ & $\begin{array}{l}5600 \\
(4200-7000)\end{array}$ \\
\hline
\end{tabular}

MI myocardial infarction, CHD coronary heart disease, QALY quality-adjusted life years

* Current guidelines: treat anyone with a history of cardiovascular disease (CVD), diabetes, or $>20 \%$ cardiovascular risk based on the Framingham Risk Score (FRS) with a moderate potency statin. Scenario 1: expand current guidelines to include those with $>10 \%$ risk based on FRS. Scenario 2: treat those qualifying under current guidelines with a high potency instead of moderate-potency statin. Scenario 3: combination of scenarios 1 and 2. All scenarios assume $50 \%$ compliance among those who qualify for but are not taking a statin

${ }^{\dagger}$ Changes in \% MIs, \% CHD deaths, and QALYs shown for simulations 1, 2, and 3 result from a comparison to the "current guidelines" simulation, which models the expansion of treatment with moderate-dose statins to $50 \%$ of those who qualify under current national guidelines but who are not currently treated with statins

₹ $50 \%$ of untreated gain the effect of going from no statin to a high-potency statin; those already on statins gain the additional LDL lowering by moving from moderate to high potency

\& Includes those currently taking statins

\section{Model Calibration}

The CVD-Policy Model-Argentina is based on assumptions originally derived from the Framingham population. Although the beta coefficients have a similar effect in different populations, ${ }^{45}$ we compared the predicted number of CHD deaths derived from the CVD Policy Model-Argentina to the actual CHD deaths captured in Argentina's vital statistics for the years 1997-2009. We used the total CHD deaths in ages 35-84 years, which included definite CHD deaths (International Statistical Classification of Diseases and Related Health Problems, 10th revision [ICD-10] codes I20-I25) plus a percentage of poorly defined deaths (named "garbage" codes) that could be attributed to CHD (ICD-10 codes I461, I469, I472, I490, I460, I500, I501, I509, I514, I515, I516, I519, I709). ${ }^{46}$ We found a difference of less than $5 \%$ between the total CHD deaths mentioned in the national statistics in the last year available $(24,246$ for 2009) and the first estimation of total CHD deaths from the CVD Policy Model (25,640 for 2010). ${ }^{1}$ Regarding stroke deaths, the difference observed was less than $10 \%$.

\section{RESULTS}

\section{Projected Impact of Change in Lipid Control Guidelines}

Estimates from the CVD Policy Model suggest that if half of those who qualified for statins under current guidelines were treated, approximately 3.7 million people would be treated. The three proposed scenarios predict a significant reduction in MIs and CHD deaths, compared with treating more people under current guidelines (Table 2). Scenario 1 (expand primary prevention with moderate statins) lowers the risk threshold to $>10 \%$ FRS and would translate into 1400 fewer MIs (95\% UI: 900-2000) and 500 fewer CHD deaths (95 \% UI: 200 800 ) every year, a $3 \%$ and $2 \%$ reduction, respectively.

Scenario 2 (high-potency statins for high-risk patients) intensifies statin potency under current guidelines; this intensification would lead to 2000 fewer MIs (95\% UI: 14002700) and 1000 fewer CHD deaths (95\% UI: 700-1300) every year. Scenario 3 (lower primary treatment threshold plus high-potency statin for high-risk patients) combines scenarios 1 and 2, and would result in the greatest reduction in MIs and CHD deaths, with 3400 fewer MIs (95\% UI: $2500-4200$ ) and 1400 fewer CHD deaths (95 \% UI: 1100-1800) every year, which translates to reductions of $7 \%$ and $6 \%$, respectively.

The combined impact on morbidity and mortality using QALYs is also illustrated in Table 3. Compared to treating more people under current guidelines, an additional 2500 (95 \% UI: 1500-3400), 3300 (95 \% UI: 2300-4300), and 5600 (95 \% UI: 4200-7000) QALYs could be gained if scenarios 1, 2, and 3 were implemented, respectively.

We also examined the number needed to treat (NNT) to avoid an MI or CHD death in the next decade (Fig. 2). Compared to baseline, an additional 39 (95\% UI: 32-47) individuals who qualify for statins under current guidelines 


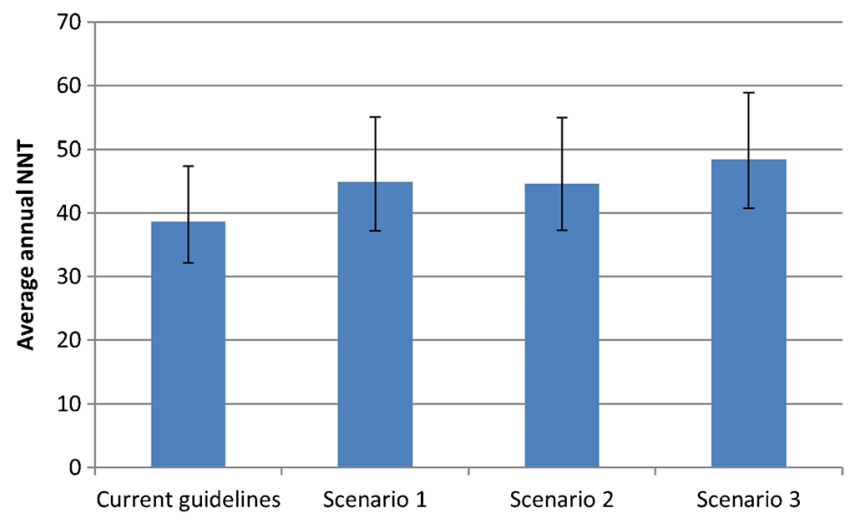

Fig. 2 Projected numbers needed to treat (NNT) annually, in addition to those currently treated, to avoid one coronary heart disease death or myocardial infarction over 10 years. Current guidelines: treat anyone with a history of cardiovascular disease (CVD), diabetes, or $>\mathbf{2 0} \%$ cardiovascular risk based on the Framingham Risk Score (FRS) with a moderate-potency statin. Scenario 1: expand current guidelines to include those with $>10 \%$ risk based on FRS. Scenario 2: treat those qualifying under current guidelines with a high-potency instead of moderate-potency statin. Scenario 3: combination of scenarios 1 and 2. To estimate the numbers needed to treat, each scenario (including "current guidelines") was compared to a simulation assuming no change in statin treatment from status quo. Numbers treated include only treatment-naïve individuals (i.e., those not on statins under status quo conditions) for the current guidelines simulation and for scenario 1 ; in scenarios 2 and 3, the total treated include those on statins at baseline who are assumed to move from a moderate- to high-potency statin. Error bars represent $95 \%$ uncertainty intervals from Monte Carlo simulation results.

but are not receiving them would need to be treated each year with a moderate-dose statin to avoid one MI or CHD death over 10 years. The corresponding NNT over 10 years to avoid a CHD death or MI for scenarios 1, 2, and 3 was 45 (95\% UI: 37-55), 45 (95\% UI: 37-55), and 48 (95\% UI: 41-59), respectively.

\section{Cost and Cost-Effectiveness Analysis}

We estimated that achieving $50 \%$ compliance with current statin use guidelines would cost approximately US $\$ 108$ million every year in medication costs. Scenario 1 would cost an additional US\$66 million per year but would save US $\$ 17$ million annually in terms of total health care costs. Scenarios 2 and 3 would cost US $\$ 15$ million and US\$21 million more, respectively, than increasing the number treated under current guidelines, but would save US\$11 million and US\$28 million in annual health care costs, respectively (Table 4).

The incremental cost-effectiveness ratio (ICER; additional cost/QALY gained) is projected to be 19,900 for scenario 1 (95 \% UI: cost saving, 66,800), 42,200 for scenario 2 (95\% UI: cost saving, 93,400), and 33,100 for scenario3 (95\% UI: 2300-67,500), with each scenario compared to increasing to $50 \%$ compliance with current guidelines. With a gross domestic product (GDP) per capita in Argentina (2009-2013) of approximately US $\$ 14,760,{ }^{47}$ all three scenarios would be considered cost-effective, as ICERs less than 1 times the per capita
GDP are typically considered very good values and ICERs 1-3 times the per capita GDP are acceptable values under the WHO guidelines on cost-effectiveness. ${ }^{48-50}$

\section{Sensitivity Analyses}

Table 5 shows results from scenarios 2 and 3 using different values for the cost of high-potency statins. Both scenarios were cost-effective at a cost per pill of US $\$ 0.25$ or lower.

Although changes in the compliance rate (25 and $75 \%$ ) modified the magnitude of events avoided, the three scenarios remained effective in terms of reducing myocardial infarctions and CHD deaths. The three scenarios remained cost-effective under a broad range of assumptions. Results were moderately sensitive to changes in compliance rate. Only scenario 2, when assuming $75 \%$ of compliance, did not remain cost-effective (ICER 48,100). Results were somewhat sensitive to the level of toxicity assumed for high-potency statins; scenario 2 was not cost-effective (ICER 51,600) when high-potency statins were assumed to have twofold increased toxicity compared to moderatedose statins. Results were not sensitive to varying discount rates.

Willingness-to-pay acceptability curves for scenarios 2 and 3 are presented in Fig. 3.

\section{DISCUSSION}

In this study, we modeled the potential health impact, cost, and cost-effectiveness of changing the national guidelines for lipid control for cardiovascular disease prevention in Argentina. We found that the three strategies examined-lowering primary prevention treatment thresholds, using high-potency statins for high-risk patients, and doing both simultaneously - would not only avoid thousands of cardiac events and deaths every year, but would also be costeffective under international criteria. ${ }^{48-50}$

These results are similar to published data from other countries, which found that $56^{51}$ to 104 people $^{52}$ needed to be treated with a statin for 5 years to avoid a major CVD event. A separate study found that high-potency statins in national guidelines could be cost-effective only if the cost of the pills were sufficiently low. ${ }^{41}$ Our study extends these observations to an Argentine context.

Our study adopts a government perspective on cost tradeoffs between medications and hospitalizations. As in many countries in Latin America, Argentina's government plays a large role in ensuring health care. In early 2014, Argentina included simvastatin in the national medication program REMEDIAR, which over the past 10 years has provided "essential drugs" at no cost to 16 million people receiving health care within the national network of primary care centers. ${ }^{53,54} \mathrm{In}$ general, in Argentina, access to essential medications such as lipid-lowering drugs has been considered a social good that 
Table 4 Projected Average Annual Costs and Cost-Effectiveness for Simulation Scenarios Compared to Current Guidelines, Estimated using the CVD Policy Model-Argentina (in US\$)

\begin{tabular}{|c|c|c|c|c|c|}
\hline $\begin{array}{c}\text { Simulation } \\
\text { scenario }\end{array}$ & $\begin{array}{l}\text { Cost of } \\
\text { intervention }^{\dagger} \\
(95 \% \text { UI })\end{array}$ & $\begin{array}{l}\text { Change in cost of } \\
\text { intervention } \\
(95 \% \text { UI })\end{array}$ & $\begin{array}{l}\text { Total health care } \\
\text { costs }{ }^{\S} \\
\text { (95\% UI) }\end{array}$ & $\begin{array}{l}\text { Change in total } \\
\text { health care costs } \\
\neq(95 \% \text { UI })\end{array}$ & $\begin{array}{l}\text { ICER }^{*} \\
\quad(95 \% \text { UI) }\end{array}$ \\
\hline $\begin{array}{l}\text { Current guidelines } \\
\text { (assumed to reach } \\
50 \% \text { currently } \\
\text { untreated) } \\
\text { (comparator) }\end{array}$ & $\begin{array}{l}107,878,000 \\
(53,594,000 \text { to } \\
160,225,000)\end{array}$ & & $\begin{array}{l}79,414,310,000 \\
(79,152,317,000 \text { to } \\
79,607,511,000)\end{array}$ & & \\
\hline $\begin{array}{l}\text { Scenario 1: expand } \\
\text { current guidelines } \\
\text { to include } 50 \% \text { of } \\
\text { FRS } 10-20 \%\end{array}$ & $\begin{array}{l}173,939,000 \\
(89,441,000 \text { to } \\
253,980,000)\end{array}$ & $\begin{array}{l}66,061,000 \\
(-31,558,000 \text { to } \\
162,110,000)\end{array}$ & $\begin{array}{l}79,397,070,800 \\
(79,134,772,000 \text { to } \\
79,591,351,000)\end{array}$ & $\begin{array}{l}-17,239,000 \\
(-13,128,000 \text { to } \\
-21,729,000)\end{array}$ & $\begin{array}{l}19,900 \text { (cost saving, } \\
66,800)\end{array}$ \\
\hline $\begin{array}{l}\text { Scenario 2: use } \\
\text { high-potency } \\
\text { statins for those } \\
\text { at risk under } \\
\text { current guidelines* }\end{array}$ & $\begin{array}{l}256,399,000 \\
(116,972,000 \text { to } \\
379,007,000)\end{array}$ & $\begin{array}{r}148,522,000 \\
(5,866,000 \text { to } \\
281,032,000)\end{array}$ & $\begin{array}{l}79,403,200,000 \\
(79,142,744,000 \text { to } \\
79,594,989,000)\end{array}$ & $\begin{array}{r}-11,110,000 \\
(-8,223,000- \\
-14,655,000)\end{array}$ & $\begin{array}{l}\text { 42,200 (cost saving, } \\
93,400)\end{array}$ \\
\hline $\begin{array}{l}\text { Scenario 3: use } \\
\text { high-potency } \\
\text { statins for those } \\
\text { at risk under } \\
\text { current guidelines*; } \\
\text { use moderate- } \\
\text { potency with } \\
\text { those } 10-20 \% \mathrm{FRS}\end{array}$ & $\begin{array}{l}322,087,800 \\
(165,585,100 \text { to } \\
492,008,500)\end{array}$ & $\begin{array}{l}214,210,300 \\
\quad(37,991,000 \text { to } \\
396,783,000)\end{array}$ & $\begin{array}{l}79,386,273,000 \\
(79,122,326,000 \text { to } \\
79,580,634,000)\end{array}$ & $\begin{array}{l}-28,036,800 \\
\quad(-22,291,000 \text { to } \\
-34,120,000)\end{array}$ & $\begin{array}{l}33,100(2300 \\
\quad \text { to } 67,500)\end{array}$ \\
\hline
\end{tabular}

ICER incremental cost-effectiveness ratio (additional cost per quality-adjusted life years gained)

$* 50 \%$ of untreated gain the effect of going from no statin to a high-potency statin; those already on statins gain the additional LDL lowering by moving from moderate to high potency

${ }^{\dagger}$ Includes cost of medication, chronic disease management related to statin delivery and assessment, and cost associated with adverse events (diabetes, stroke, and myopathy)

Changes in costs and ICERs are computed for each scenario relative to a simulation assuming current guidelines are expanded to reach $50 \%$ of the untreated population

$\S$ Includes costs associated with coronary heart disease, stroke, and background health care costs

should be made readily available to all. ${ }^{55}$ As the government also bears the costs of CVD hospitalization for approximately $40 \%$ of the population, cost-effectiveness studies such as this one are highly relevant for government policymakers.

Argentina has used evidence-based strategies in the past to inform national policy. For example, other modeling studies using the CVD Policy Model-Argentina on tobacco control ${ }^{13}$ and salt consumption ${ }^{14,15}$ suggested policies that were subsequently implemented. Other Latin American countries including Chile and Brazil also have national CVD prevention guidelines $^{56,57}$ that focus on lipids; modeling exercises like this one, which are commonly used, for example, in countries of the United Kingdom, ${ }^{58}$ can be instrumental in the development of evidence-based guidelines that incorporate resource impact.

Given the limited resources available, only those interventions that can lead to large reductions in the CVD burden at relatively low cost are likely to be sustainable. ${ }^{59}$ The scenarios modeled in this study highlight the importance of lipid-lowering drugs and guidelines for cardiovascular disease prevention in Argentina. Two of our scenarios extend drug treatment to large numbers of the

Table 5 Projected Cost and Cost-Effectiveness Outcomes Assuming Varying Costs of High-Potency Statins, Estimated Using the CVD Policy Model-Argentina (in US\$)

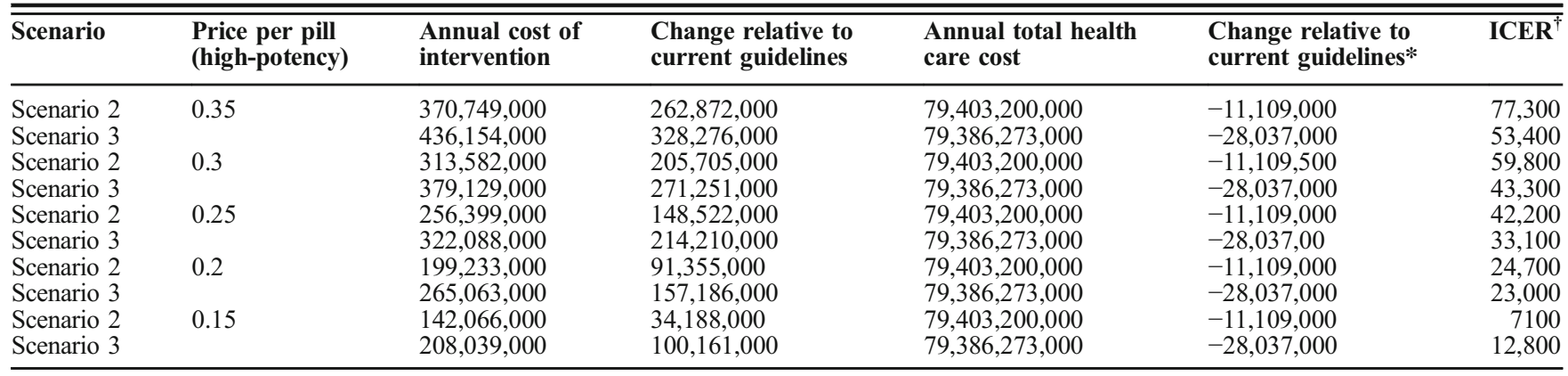

*Differences between each scenario and the base case of current guidelines are shown in parentheses

${ }^{\dagger} I C E R=$ incremental cost-effectiveness ratio (additional cost per quality-adjusted life years gained). ICERs are relative to the base case of current guidelines 


\section{Acceptability curves}
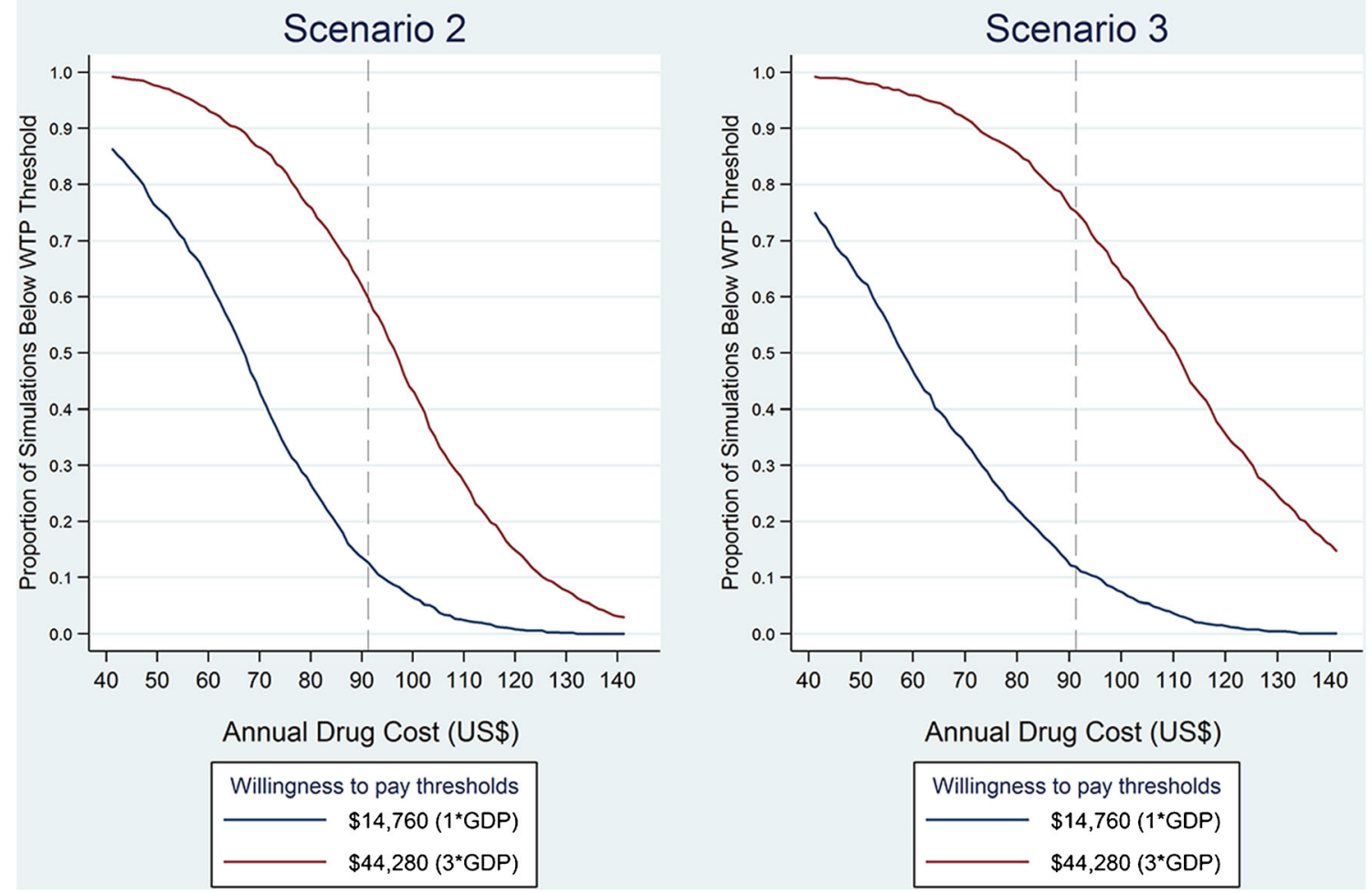

Fig. 3 Willingness-to-pay acceptability curves.

population. This raises the potential for "over-medicalization" and for the tacit acceptance of unhealthy elements of the Argentine diet. We made no attempt to consider other alternatives, such as government-funded social marketing campaigns that could contribute to sustained cholesterol lowering, as we have no data on their effectiveness from an Argentine perspective. Much more research on the effective promotion of broad changes in diet is needed in Argentina and in Latin America as a whole.

Some other limitations of our study should be considered. We assumed that everyone who was currently on statin therapy in Argentina was treated with a moderatepotency statin, as is currently suggested by national guidelines. As there are no national data available on which statins patients are actually using, we were unable to test this assumption. Second, as noted, we considered the health care costs from the government's perspective; these results might not be generalizable to the private health sector, which has different health care costs. Finally, all modeling studies are limited by the integrity of their inputs. We used the best available data from Argentina to adapt the US CVD Policy Model for Argentina. Although there is debate on how relevant the Framingham Risk Score is to non-US populations, ${ }^{60}$ because of a lack of Argentine data, we used the Framingham data to determine the association between CVD risk factors and CVD outcomes. Prior studies adapting Framingham to other international contexts have suggested that the associations between risk factors and CVD events (beta) appear to be similar across populations, although actual event rates (alpha) may differ among populations. ${ }^{61}$ Event rates for the CVD Policy Model-Argentina were calibrated with the best available epidemiological data from Argentina, comparing the predictions of the CVD Policy Model with local vital statistics; differences in event rate are less than $5 \%$. Previously published papers have used the CVD Policy Model to accurately predict outcomes in the Argentine population, which increases our confidence in the model's accuracy. ${ }^{13-15,62}$

Despite these limitations, we believe that this study contributes to the ongoing debate in Argentina by projecting the health benefits of three possible strategies for lipid control in cardiovascular disease prevention. To our knowledge, this study is the first to analyze the impact of current national guidelines for cardiovascular disease prevention in Latin America or to model alternatives to current guidelines based on lowering the primary prevention threshold or treating highrisk patients with high-potency statins, as is currently recommended in many other international guidelines. Incorporating modeling strategies in the development of national guidelines could help provide a better understanding of cost-effective interventions in the region. This type of approach may also be useful in the future for modeling additive interventions in this population, such as control of hypertension and use of low-dose aspirin. The data provided here should be key inputs 
for policymakers who seek to improve cardiovascular disease prevention in Argentina.

Corresponding Author: Jonatan Konfino, MSc; Centro de Estudios de Estado y Sociedad (CEDES), Buenos Aires, Argentina (e-mail:jkonfino@gmail.com).

\section{Compliance with Ethical Standards:}

Disclaimer: The content and views expressed in this manuscript are those of the authors and should not be construed to represent the views of the National Institutes of Health or any of the sponsoring organizations and agencies of the US government.

Funding: Dr. Fernandez was supported by grant K24DK102057 from the National Institutes of Health (NIH) and National Institute of Diabetes and Digestive and Kidney Diseases (NIDDK).

Conflict of Interest: The authors declare that they do not have a conflict of interest.

\section{REFERENCES}

1. Ministerio de Salud de la Nación. ESTADISTICAS VITALES - INFORMACION BASICA AÑO 2014. In: DIRECCION DE ESTADISTICAS E INFORMACION DE SALUD, ed. http://deis.msal.gov.ar/wp-content/ uploads/2016/07/BoletinNro153.pdf. Accessed: October 12, 2016.

2. Ministerio de salud de la Nación, Instituto Nacional de Estadística y Censos. Tercera Encuesta Nacional de Factores de Riesgo. Resumen ejecutivo. Buenos Aires; 2014.

3. Yusuf S, Islam S, Chow CK, Rangarajan S, Dagenais G, Diaz R, et al. Use of secondary prevention drugs for cardiovascular disease in the community in highincome, middle-income, and low-income countries (the PURE study): a prospective epidemiological survey. Lancet. 2011;378(9798):1231-1243.

4. Johansen ME, Green LA, Sen A, Kircher S, Richardson CR. Annals journal club: cardiovascular risk and statin use in the United States. Ann Fam Med. 2014;12(3):215-23.

5. Ansell BJ, Watson KE, Fogelman AM. An evidence-based assessment of the NCEP adult treatment panel II guidelines. National cholesterol education program. JAMA. 1999;282(21):2051-2057.

6. Prosser LA, Stinnett AA, Goldman PA, Williams LW, Hunink MG, Goldman L, et al. Cost-effectiveness of cholesterol-lowering therapies according to selected patient characteristics. Ann Intern Med. 2000;132(10):769-779.

7. Minder CM, Blaha MJ, Horne A, Michos ED, Kaul S, Blumenthal RS. Evidence-based use of statins for primary prevention of cardiovascular disease. Am J Med. 2012;125(5):440-446.

8. Mortensen MB, Falk E. Real-life evaluation of European and American high-risk strategies for primary prevention of cardiovascular disease in patients with first myocardial infarction. BMJ Open. 2014;4(10):e005991.

9. Stone NJ, Robinson J, Lichtenstein AH, Bairey Merz CN, Blum CB,

Eckel RH, et al. 2013 ACC/AHA guideline on the treatment of blood cholesterol to reduce atherosclerotic cardiovascular risk in adults: a report of the American College of Cardiology/American Heart Association Task Force on Practice Guidelines. Circulation. 2013.

10. Ministerio de Salud de la Nación. Factibilidad de Implementación de un sistema de vigilancia telefónico para factores de riesgo de enfermedades crónicas no transmisibles. Bol Vigilancia. 2011;5:5-21.

11. Weinstein M, Coxson P, Williams L, Pass T, Stason W, Goldman L. Forecasting coronary heart disease incidence, mortality, and cost: the coronary heart disease policy model. Am J Public Health. 1987;77(11):1417-1426.

12. Moran AE, Odden MC, Thanataveerat A, Tzong KY, Rasmussen PW, Guzman D, et al. Cost-effectiveness of hypertension therapy according to 2014 guidelines. N Engl J Med. 2015;372(5):447-455.

13. Konfino J, Ferrante D, Mejía R, Coxson P, Moran A, Goldman L, et al. Impact on cardiovascular disease events of the implementation of Argentina's national tobacco control law. Tob Control. 2012.
14. Konfino J, Mekonnen TA, Coxson PG, Ferrante D, Bibbins-Domingo K. Projected impact of a sodium consumption reduction initiative in Argentina: an analysis from the CVD policy model - Argentina. PLoS One. 2013;8(9):e73824.

15. Ferrante D, Konfino J, Mejia R, Coxson P, Moran A, Goldman L, et al. Relación de la costo utilidad de la disminución del consumo de sal y su efecto en la incidencia de enfermedades cardiovasculares en la Argentina. Rev Panam Salud Pública. 2012;32(4):274-280.

16. Framingham Heart Study-Cohort (FHS-Cohort) data request site. Biologic Specimen and Data Repository Information Coordinating Center: National Heart L, and Blood Institute. Available from: http://biolincc.nhlbi.nih.gov/ studies/framcohort/?q=framingham. Accessed: October 12, 2016.

17. Framingham Heart Study-Offspring Study (FHS-OS) data request site. Biologic Specimen and Data Repository Information Coordinating Center: National Heart L, and Blood Institute. Available from: http://biolincc.nhlbi. nih.gov/studies/framoffspring/?q=framingham. Accessed: October 12, 2016.

18. Dawber TR. The Framingham Study: the epidemiology of atherosclerotic disease. Cambridge, MA1980

19. Feinleib M, Kannel WB, Garrison RJ, McNamara PM, Castelli WP. The Framingham offspring study. Design and preliminary data. Prev Med. 1975;4(4):518-525.

20. Kleinbaum DG, Klein M. Survival analysis: a self-learning text. New York: Springer; 2012:366-379.

21. Instituto Nacional de Estadísticas y Censos. Ministerio de Economía. 2011 [cited 2016 October 12]. Available from: www.indec.gov.ar

22. Ministerio de Salud de la Nación. Segunda Encuesta Nacional de Factores de Riesgo. Buenos Aires: Ministerio de Salud de la Nación; 2011.

23. Schargrodsky $H$, Hernandez-Hernandez R, Champagne B, Silva $\mathbf{H}$, Vinueza R, Silva Aycaguer L, et al. CARMELA: assessment of cardiovascular risk in seven Latin American cities. Am J Med. 2008;1(121):58-65.

24. Caccavo A, Alvarez A, Bello F, Ferrari A, Carrique A, Lasdica S, et al. Incidencia poblacional del infarto con elevación del ST o bloqueo de rama izquierda a lo largo de 11 años en una comunidad de la provincia de Buenos Aires. Rev Argent Cardiol. 2007;75:185-188.

25. Ministerio de Salud de la Nación. ESTADISTICAS VITALES - INFORMACION BASICA AÑO 2010. In: DIRECCION DE ESTADISTICAS E INFORMACION DE SALUD, ed. 2012: http://deis.msal.gov.ar/wp-content/ uploads/2016/01/Boletin 136.pdf

26. Blanco P, Gagliardi J, Higa C, Dini A, Guetta J, Di Toro D, et al. Infarto agudo de miocardio. Resultados de la Encuesta SAC 2005 en la República Argentina. Rev Argent Cardiol. 2007;75:163-179.

27. Sposato L, Esnaola M, Zamora R, Zurru M, Fustinoni O, Saposnik G. Quality of ischemic stroke care in emerging countries: the Argentinean national stroke registry (ReNACer). Stroke. 2008;39:3036-3041.

28. Lavados P, Sacks C, Prina L, Escobar A, Tossi C, Araya F, et al. Incidence, 30-day case-fatality rate, and prognosis of stroke in Iquique, Chile: a 2-year community-based prospective study (PISCIS project). Lancet. 2005;365(9478):2206-2215.

29. Stone NJ, Robinson JG, Lichtenstein AH, Bairey Merz CN, Blum CB, Eckel RH, et al. 2013 ACC/AHA guideline on the treatment of blood cholesterol to reduce atherosclerotic cardiovascular risk in adults: A report of the American College of Cardiology/American Heart Association Task Force on Practice Guidelines. J Am Coll Cardiol. 2014;63:2889-2934.

30. Cholesterol Treatment Trialists' Collaborators MB, Emberson J, Blackwell L, Keech A, Simes J, Barnes EH, Voysey M, Gray A, Collins R, Baigent C. The effects of lowering LDL cholesterol with statin therapy in people at low risk of vascular disease: meta-analysis of individual data from 27 randomised trials. Lancet. 2012;380(9841):581590.

31. K@iros. Revista de Ciencia y Tecnologia para su farmacia 2014 [cited 2014 February 20th]. Available from: http://ar.kairosweb.com/laboratorios/ producto-simvastatina-fabra-20519, http://ar.kairosweb.com/laboratorios/producto-atorvastatina-fabra-19965

32. Base de Datos de Costos Sanitarios Argentinos, Documento Técnico №3 [Internet]. 2010.

33. Nomenclador Bioquímico Único - PMO y Prácticas Especiales- Versión 2010. Confederación Unificada Bioquímica de la Republica Argentina.

34. The Institute for Health Metrics and Evaluation. Global burden of disease study 2010 Disability Weights 2010 [cited 2016 October 12]. Available from: http://ghdx.healthdata.org/record/global-burden-disease-study2010-gbd-2010-disability-weights

35. Sattar N, Preiss D, Murray HM, Welsh P, Buckley BM, de Craen AJ, et al. Statins and risk of incident diabetes: a collaborative meta-analysis of randomised statin trials. Lancet. 2010;375(9716):735-742.

36. Nomenclador del Hospital Público de Gestión DescentralizadaActualización 2011- Ministerio de Salud de la Republica Argentina. 
37. Instituto Nacional de Estadística y Censos. Índice de Precios al Consumidor - Capítulo: Atención Médica y Gastos para la Salud. 2011.

38. Pichon-Riviere A AA, Bardach A, Augustovski F, Caporale J, Caccavo F. Carga de Enfermedad atribuible al Tabaquismo en Argentina. Documento Técnico IECS $N^{\circ}$ 7. Instituto de Efectividad Clínica y Sanitaria, Buenos Aires, Argentina. Mayo de 2013 (www.iecs.org.ar).

39. Riapari N, MoscosoN, Budassi N. Estudio de Costos de Cirugias Cardiovasculares. Anales de la Asociación Argentina de Economía Política. 2010.

40. Rubinstein A, Colantonio L, Bardach A, Caporale J, Marti SG, Kopitowski K, et al. Estimation of the burden of cardiovascular disease attributable to modifiable risk factors and cost-effectiveness analysis of preventative interventions to reduce this burden in Argentina. BMC Public Health. 2010;10:627.

41. Pletcher MJ, Lazar L, Bibbins-Domingo K, Moran A, Rodondi N, Coxson P, et al. Comparing impact and cost-effectiveness of primary prevention strategies for lipid-lowering. Ann Intern Med. 2009;150(4):243-254.

42. Borraci R, Rubio M, Insua J. Análisis de costos médicos y resultados de la cirugía coronaria sin circulación extracorpórea. Rev Argent Cardiol. 2006;74(5).

43. Ministerio de Salud de la Nación, Programa REMEDIAR + Redes, Personal Communication. 2014

44. Drummond MF, Sculpher MJ, Claxton K, Stoddart GL, Torrance GW. Methods for the economic evaluation of health care programmes. Fourthth ed. Oxford: Oxford University Press; 2015.

45. D'Agostino R, Grundy S, Sullivan LM, Wilson P. CHD Risk Prediction Group. Validation of the Framingham coronary heart disease prediction scores: results of a multiple ethnic groups investigation. JAMA. 2001;286(2):180-187.

46. Naghavi M, Foreman K, O'Brien J, Pourmalek F, Lozano R. Algorithms for enhancing public health utility of national causes-of-death data. Popul Health Metrics. 2010;8(9).

47. World Bank. GDP per capita 2015 [cited 2015 september 25th]. Available from: http://data.worldbank.org/indicator/NY.GDP.PCAP.CD

48. Ferrante D, Lew D, Peruga A, Compton C, Romano E. The role of public policies in reducing smoking prevalence and deaths: the Argentina tobacco policy simulation model. Rev Panam Salud Pública. 2007;21(1):37-49.

49. Levy DT, Nikolayev L, Mumford EA. Recent trends in smoking and the role of public policies: results from the SimSmoke tobacco control policy simulation model. Addiction. 2005;100(10):1526-1537.

50. World Health Organization. Who Guide to Cost - Effectiveness Analysis 2003. Available from: http://www.who.int/choice/publications/p_2003 generalised_cea.pdf
51. Taylor F HM, Macedo A, Moore THM, Burke M, Davey Smith G, Ward K, Ebrahim S. Statins for the primary prevention of cardiovascular disease. Cochrane Database Syst Rev 2013, Issue 1. Art. No.: CD004816; doi: 10. 1002/14651858.CD004816.pub5.

52. Ray KK, Seshasai SR, Erqou S, Sever P, Jukema JW, Ford I, et al. Statins and all-cause mortality in high-risk primary prevention: a metaanalysis of 11 randomized controlled trials involving 65,229 participants. Arch Intern Med. 2010;170(12):1024-1031. doi:10.1001/archinternmed. 2010.182.

53. Ministerio de Salud de la Nación. Programa REMEDIAR + Redes. Available from: http://www.msal.gov.ar/

54. Cerezo L, Dias JM, Fernández Prieto A, La Cava G, Luque PS, Monsalvo $\mathbf{M}$, et al. Impacto redistributivo del programa Remediar en el gasto en medicamentos: estudio cuantitativo. Rev Argent Salud Pública. 2014;5(20):40-43.

55. Dondo M, Monsalvo M, Garibaldi L. Determinants of equity in financing medicines in Argentina: an empirical study. Cad Saúde Pública. 2016;32(1):1-14.

56. Ministerio de Salud de Chile. Dislipemias 2000. Available from: http://www. minsal.gob.cl/portal/url/item/75fefc3f8128c9dde04001011f0178d6.pdf

57. Ministerio da Saude Brazil. DISLIPIDEMIA: PREVENÇÃO DE EVENTOS CARDIOVASCULARES E PANCREATITE 2013 [cited 2016 October 12]. Available from: http://portalsaude.saude.gov.br/images/pdf/2014/abril/ 02/pcdt-dislipidemia-livro-2013.pdf

58. NICE. National Institute for Health and care Excellence. [cited 2016 October 12]. Available from: https://www.nice.org.uk/gui

59. Gaziano TA. Cardiovascular disease in the developing world and its costeffective management. Circulation. 2005;112(23):3547-3553.

60. Cortes-Bergoderi M, Thomas RJ, Albuquerque FN, Batsis JA, Burdiat G, Perez-Terzic C, et al. Validity of cardiovascular risk prediction models in Latin America and among Hispanics in the United States of America: a systematic review. Rev Panam Salud Publica. 2012;32(2):131-139.

61. D'Agostino RB Sr, Grundy S, Sullivan LM, Wilson P, CHD Risk Prediction Group. Validation of the Framingham coronary heart disease prediction scores: results of a multiple ethnic groups investigation. JAMA. 2001;286(2):180-187.

62. Moran A, Degennaro V, Ferrante D, Coxson P, Palmas W, Mejía R, et al. Coronary heart disease and stroke attributable to major risk factors is similar in Argentina and the United States: the coronary heart disease policy model. Int J Cardiol. 2011;150(3):332-337. 